\title{
Retraction Note to: Endometrial cancer presenting as acute urinary retention: a case report and review of the literature
}

Samer Tannus ${ }^{*}$ and Ilan Atlas

\section{Retraction note}

This article [1] has been retracted by the publisher because it was republished in the journal [2] due to an error during transfer of the journal between publishers in 2009. BioMed Central apologizes to the authors and readers for this error and for any inconvenience caused.

\section{References}

1. Tannus SR, Atlas I. Endometrial cancer presenting as acute urinary retention: a case report and review of the literature. Cases J. 2009;2:9388.

2. Tannus SR, Atlas I. Endometrial cancer presenting as acute urinary retention: a case report and review of the literature. Cases J. 2009;2:9382. 